\title{
Comparison of marginal microleakage of metal copings cemented with three luting cements
}

\author{
Keyla Vargas-Belón ${ }^{1}$, Katya Chambilla-Torres ${ }^{2}$, Marco Sánchez-Tito ${ }^{2}$ \\ ${ }^{1}$ Private practice, Tacna, Peru \\ ${ }^{2}$ Facultad de Ciencias de la Salud, Universidad Privada de Tacna, Tacna, Peru
}

\author{
Correspondence: \\ Facultad de Ciencias de la Salud \\ Universidad Privada de Tacna \\ Av. Jorge Basadre Grohmann $s / n$ \\ Tacna, Perú \\ marcosanchez2183@gmail.com
}

Received: 01/01/2022

Accepted: 06/02/2022

\begin{abstract}
Vargas-Belón K, Chambilla-Torres K, Sánchez-Tito M. Comparison of marginal microleakage of metal copings cemented with three luting cements. J Clin Exp Dent. 2022;14(3):e280-4.
\end{abstract}

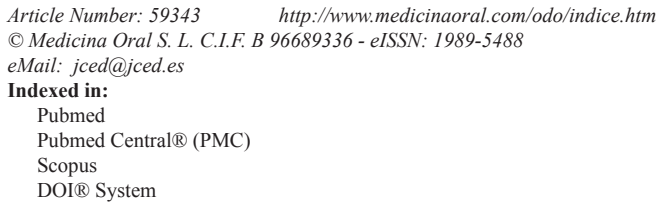


caries at the tooth-material interface $(3,4)$. The latter phenomenon is one of the main reasons for the failure of crown restorations (5). The key factors to ensure crowns' longevity and clinical success are fracture resistance and marginal adaptation (6).

Cementation is essential for the long-term prognosis of crowns, as it seals the dead space (cement space), provides retention, prevents microleakage and secondary caries (7).

Various types of cements are currently available, from traditional cements such as zinc phosphate cement to resin-based or resin-modified cements. Zinc phosphate cement has been used in dentistry since the 1880s; it has a successful track record supported by clinical evidence, but due to its high solubility and low adhesion, it has high in vitro microleakage scores compared to other cements; despite this, this cement ensures the survival of crowns in the mouth, especially metal-ceramic and metal crowns (8-10). In the case of glass ionomer cement, its ability to adhere to the tooth structure and release fluoride is recognized, which is why its use has increased in recent decades. In addition, it has low solubility and disintegration values compared to other cements, thus reducing the percentage of microleakage (11). Over time, its composition underwent several modifications; the addition of resin to its composition allowed the uptake and release of calcium, fluoride, and phosphate ions in reaction to changes in $\mathrm{pH}$ in the oral environment; this bioactivity allowed better chemistry and bonds between the cement and dentin, thus reducing microleakage, improving durability and remineralization of the tooth (7). Although there is no ideal luting agent that meets all the expected requirements, it is essential to consider the factor of microleakage when choosing one of these materials. Previous studies have analyzed the degree of marginal sealing of crowns concerning the type of cement used. Behnaz et al. showed that resin-modified cements have lower microleakage than glass ionomer and zinc phosphate cements, the latter having the highest microleakage values (12). Al-Haj et al. observed that glass ionomer cement had the highest microleakage compared to resin-modified cement and resin-based cement (13). Satyendra et al. studied the behavior of resin and resin-modified glass ionomer cements and showed that the resin-based cement produced less microleakage (14). The objective of this study was to compare marginal microleakage in single-unit metal copings cemented with zinc phosphate, glass ionomer, and modified ionomer.

\section{Material and Methods}

-Design and sample calculation

An in vitro experimental study was performed. The calculation of the sample was determined using the $\mathrm{G}^{*}$ Power program. An effect size of 0.5 , a significance level of 0.05 , and a power of 0.8 were considered. Fif- teen samples were estimated for each group. Prior to the execution of the study, authorization was obtained from the Ethics Committee of the Faculty of Health Sciences of the Universidad Privada de Tacna under registry no. 014-2020-FACSA/UPT.

-Sample preparation

Forty-five healthy premolars, extracted for orthodontic reasons, collected from various private dental centers in the city of Tacna, Peru, were used. The teeth were immersed in $2.5 \%$ sodium hypochlorite for $24 \mathrm{~h}$ to eliminate soft tissue debris and washed copiously with running water (13). Test tubes were made by immersing the teeth in Vitacryl self-curing acrylic (New Stetic, Antioquia, Colombia) up to $1 \mathrm{~mm}$ from the amelocemental junction. Then, the teeth were prepared, considering a chamfer-type shoulder preparation with an angulation of $6^{\circ}$ (15), verified with a parallelogram (Bioart, Sao Paulo, Brazil). Coarse and fine-grained round-tipped truncated cone-shaped diamond burs (MDT, Israel) were used for the preparation. Subsequently, impressions of each test tube were taken with Zeta plus Oranwash - L condensation silicone (Zhermack, Badia Polesine, Italy) using polyvinyl chloride (PVC) tubes as specimens. The impressions were vacuum cast to obtain working models with type IV Resinrock plaster (WhipMix, Kentucky, USA). A Fornax -T induction furnace (BEGO, Bremen, Germany) was used to make the metal copings.

-Cementation and marginal seal measurement

Prior to cementation, the sealing of the copings was verified using an explorer and fluid silicone technique. In the test tubes where misalignment of the copings was found, the manufacturing process was repeated. Samples were randomly assigned into three groups depending on the type of cement used for cementation: Prothoplast Zinc Phosphate (Laboratorios SL S.A., Buenos Aires, Argentina), Ketac-Cem Easymix glass ionomer (3M-ESPE, Neuss, Germany) and Relyx ${ }^{\mathrm{TM}}$ Luting 2 resin-modified ionomer (3M-ESPE, Saint Paul Minnesota, USA). The cements were prepared according to their manufacturers' recommendations. Once set, the samples were immersed in 2\% methylene blue solution for 24 hours (17). Microleakage was measured with a 40x stereomicroscope (Carl Zeiss Light Microscopy, Göttingen, Germany) using four measuring points: vestibular, palatal, mesial, and distal (Fig. 1).

-Data analysis

Data analysis was performed with the statistical program (SPSS- Statistical Package for the Social Sciences) version 25.0. The assumptions of normality and homogeneity of variances were checked with the Shapiro Wilk and Levene tests, respectively. The data was analyzed for the averages of each measurement point, and additionally, to this, the overall average for each cement was analyzed. The ANOVA test followed by the Scheffé test for multiple comparisons of marginal microleakage me- 


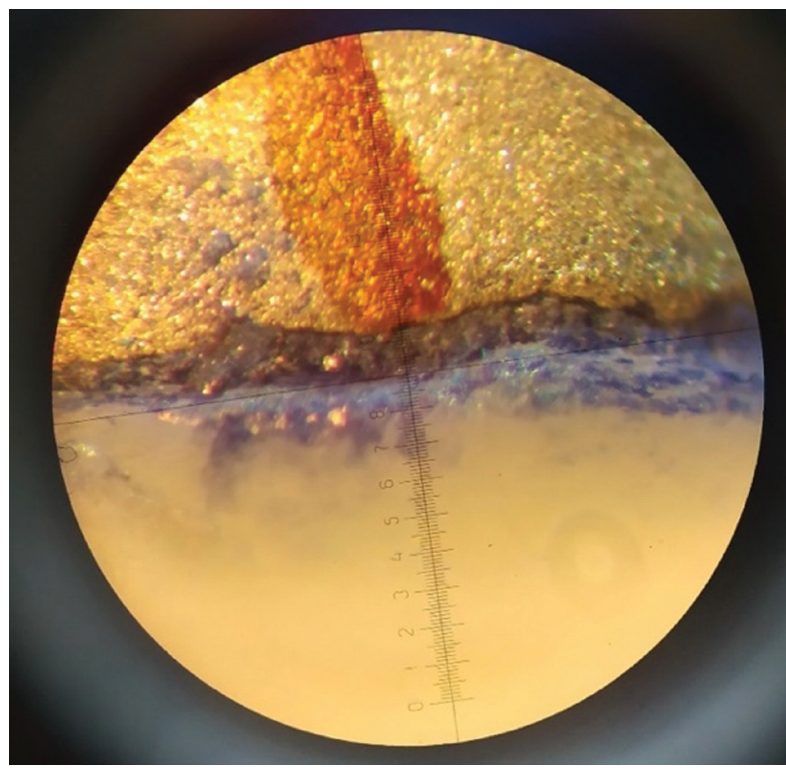

Fig. 1: Measurement of microleakage at one of the sample reference points.

asurements was used to evaluate the difference between measurements. The significance level was adjusted to $5 \%$.

\section{Results}

Table 1 shows the average marginal microleakage produced by the cements. Glass ionomer cement showed the lowest microleakage values $(98.64 \pm 39.18 \mu \mathrm{m})$, al- though no significant differences were observed with the other cements $(p>0.05)$.

Table 2 highlights that in the case of zinc phosphate cement, a higher microleakage was observed on the lingual side with values of $124.13 \pm 54.76 \mu \mathrm{m}$; in the case of glass ionomer cement, the highest values were observed on the distal side with $114.38 \pm 36.17 \mu \mathrm{m}$, while in the case of resin-modified ionomer cement the mesial side was the one that obtained the highest microleakage values with $118.81 \pm 36.75 \mu \mathrm{m}$. However, no significant statistical differences were observed between the groups when the ANOVA test followed by the Scheffé test was performed $(p>0.05)$.

The figure 2 shows a higher marginal microleakage on the vestibular side for the resin-modified ionomer cement $(110.83 \pm 52.16 \mu \mathrm{m})$, while for the lingual side it was the zinc phosphate cement $(87.78 \pm 51.46 \mu \mathrm{m})$, for the mesial side, it was again the resin-modified ionomer cement $(118.81 \pm 36.75 \mu \mathrm{m})$ and for the distal side the glass ionomer cement $(114.38 \pm 36.17 \mu \mathrm{m})$.

\section{Discussion}

The appropriate selection of a luting agent is a relevant decision for the success of fixed restorations. The presence of marginal gaps and microleakage can affect their long-term permanence in the mouth $(14,16)$. In the literature, the marginal sealing capacity of different cements used in the crown cementation process has been studied in order to demonstrate which one avoids or decreases marginal microleakage.

Table 1: Average microleakage in cemented copings with the three cements $(\mu \mathrm{m})$.

\begin{tabular}{|l|c|c|c|c|c|}
\hline Cement & Media & SD & Minimum & Maximum & $\boldsymbol{p}$ value* \\
\cline { 1 - 5 } Zinc Phosphate & 109.28 & 51.27 & 13.3 & 239.4 & \multirow{2}{*}{0.374} \\
\cline { 1 - 5 } Glass ionomer & 98.64 & 39.18 & 15.9 & 186.2 & \\
\cline { 1 - 3 } Ionomer modified with resin & 102.63 & 45.07 & 26.6 & 212.8 & \\
\hline
\end{tabular}

SD: standard deviation.

* ANOVA test

Table 2: Microleakage in the cemented copings with the three cements for each measuring point $(\mu \mathrm{m})$.

\begin{tabular}{|l|c|c|c|c|c|}
\hline \multirow{2}{*}{ Cement } & \multicolumn{4}{|c|}{ Marginal microleakage (mm) } & \multirow{2}{*}{$\boldsymbol{p}$ value* } \\
\cline { 2 - 6 } & $\begin{array}{c}\text { Vestibular } \\
(\text { Mean } \pm \text { SD) }\end{array}$ & $\begin{array}{c}\text { Lingual } \\
(\text { Mean } \pm \text { SD) }\end{array}$ & $\begin{array}{c}\text { Mesial } \\
(\text { Mean } \pm \text { SD) }\end{array}$ & Distal (Mean \pm SD) & \\
\hline Zinc phosphate & $87.78 \pm 51.46^{\mathrm{Aa}}$ & $124.13 \pm 54.76^{\mathrm{Ba}}$ & $117.92 \pm 54.11^{\mathrm{Ba}}$ & $105.51 \pm 42.19^{\mathrm{Ba}}$ & 0.227 \\
\hline Glass ionomer & $96.82 \pm 38.69^{\mathrm{Ab}}$ & $99.12 \pm 52.72^{\mathrm{Aa}}$ & $84.23 \pm 29.16^{\mathrm{Bb}}$ & $114.38 \pm 36.17^{\mathrm{Aa}}$ & 0.244 \\
\hline $\begin{array}{l}\text { Ionomer modified } \\
\text { with resin }\end{array}$ & $110.83 \pm 52.16^{\mathrm{Ab}}$ & $86.89 \pm 49.47^{\mathrm{Bb}}$ & $118.81 \pm 36.75^{\mathrm{Aa}}$ & $93.98 \pm 41.89^{\mathrm{Ab}}$ & 0.205 \\
\hline$p$ value* & 0.420 & 0.152 & 0.042 & & 0.387 \\
\hline
\end{tabular}

SD: standard deviation.

* ANOVA test followed by Scheffé's post hoc test for multiple comparisons.

Different letters within columns and rows indicate differences in averages. 


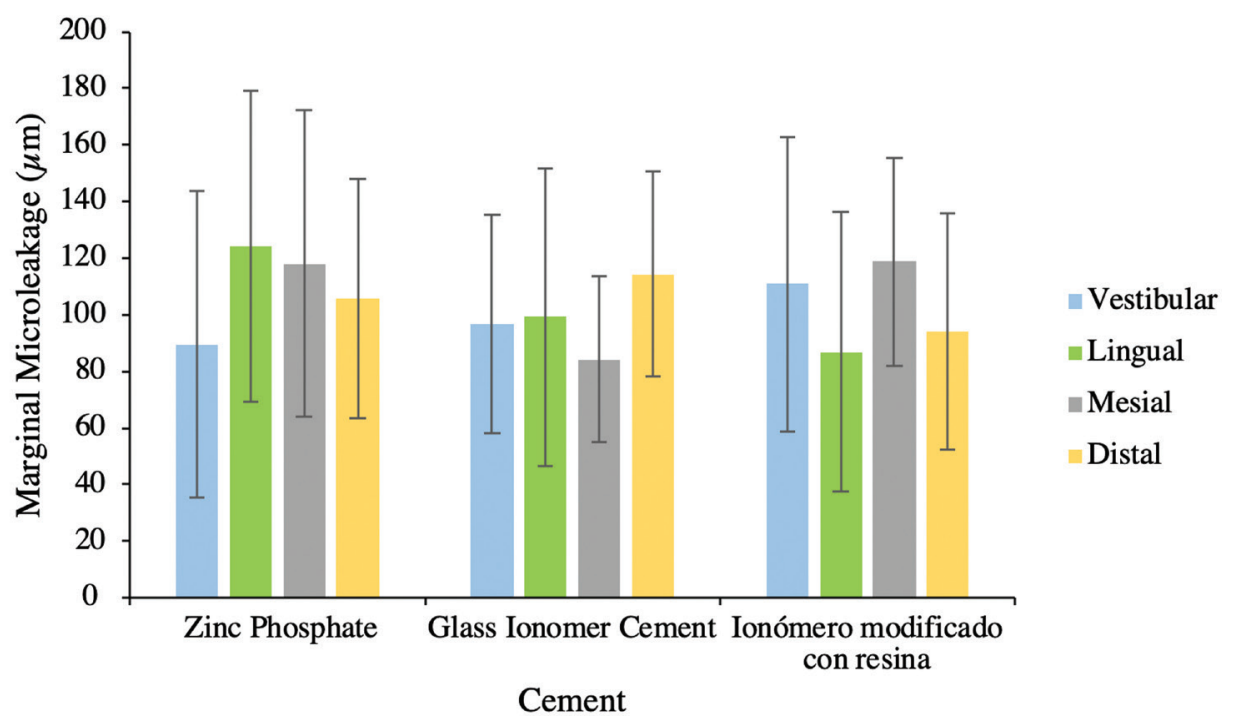

Fig. 2: Marginal leakage error bars for cemented copings with the three cements per measurement point.

Ebadian et al. (12) studied the microleakage of restorations cemented with RelyX ${ }^{\mathrm{TM}}$ Ultimate, RelyX ${ }^{\mathrm{TM}}$ Unicem, GC Gold Label, and Hoffmann cements, finding that Hoffmann zinc phosphate cement obtained higher microleakage values $(5.00 \pm 2.000 \mathrm{~mm})$ followed by $\mathrm{GC}$ Gold Label glass ionomer cement $(2.71 \pm 1,976 \mathrm{~mm})$ and finally by the resinous cements RelyX ${ }^{\mathrm{TM}}$ Unicem $(2.14 \pm 1.952 \mathrm{~mm})$ and RelyX $\mathrm{X}^{\mathrm{TM}}$ Ultimate $(0.86 \pm 1.215$ $\mathrm{mm})$, considering the nature of the cements, these results are similar to those found in the present study, where the zinc phosphate cement presented higher microleakage versus the glass ionomer cement.

Parameswari et al. (17) observed that Harvard's zinc phosphate ${ }^{\circledR}$ cement had the highest microleakage values $(82.6 \pm 3.64 \mu \mathrm{m})$ followed by Multilink ${ }^{\circledR}$ resinous cement $(57.6 \pm 3,435 \mu \mathrm{m})$ while Fuji's GC glass ionomer cement $^{\circledR}$ had the lowest values $(28.6 \pm 5,413 \mu \mathrm{m})$. The study by Eftekhar et al. (18) showed that Fleck's zinc phosphate cement obtained the highest microleakage results $(3.32 \pm 0.70 \mathrm{~mm})$, followed by G-Cem ${ }^{\mathrm{TM}}$ resin cement $(2.08 \pm 1.10 \mathrm{~mm})$, Fuji Plus ${ }^{\circledR}$ resin-modified glass cement $(0.92 \pm 0.53 \mathrm{~mm})$ and finally PanaviaTM F2.0 resin cement $(0.64 \pm 0.78 \mathrm{~mm})$. Al-Haj et al. (13) observed that Ketac Cem Aplicap ${ }^{\mathrm{TM}}$ glass ionomer cement obtained higher microleakage results $(0.67 \pm 0.27 \mathrm{~mm})$ while lower values were recorded for Rely $\mathrm{X}^{\mathrm{TM}}$ Unicem $(0.30 \pm 0.30 \mathrm{~mm})$. Satyendra et al. (14) showed that Relyx Lut U 200 resin cement obtained lower microleakage values $(64.04 \pm 7.44 \mu \mathrm{m})$ when compared to Relyx Lut 2 resin-modified ionomer cement $(74.26 \pm 7.67$ $\mu \mathrm{m})$. These results suggest that zinc phosphate cement has higher marginal microleakage than glass ionomer and resin-modified ionomer cements; this characteristic was similar in the present study, although the differences between the level of microleakage between the types of cements were not statistically significant.

The difference in microleakage between cements reported in previous studies could be explained by the various components that can affect their properties. Zinc phosphate cement is a type of acid-base cement used mainly as a cementing agent, known for its clinical use in the routine cementation of metal-supported crowns and bridges (17). It is characterized by a low $\mathrm{pH}$ of 2 to 4 when the powder is mixed with the liquid, the $\mathrm{pH}$ increases during setting to reach neutrality in one to two days $(8,9)$. The initial acidic environment will cause an increase in solubility, causing slow erosions due to a combination of abrasions and dissolutions, resulting in microleakage points. Despite this, it has one of the highest survival rates with respect to crowns in the mouth (10).

Type I glass ionomer is exclusive for cementation. It is characterized by superior adhesion to dental tissues and a low coefficient of exothermic expansion, similar to dentin, acting as a thermal insulator, thus reducing possible future microleakage (19). In addition, although this cement has an initial acid $\mathrm{pH}$, it neutralizes quickly, so it would not influence later problems (11). On the other hand, the resin-modified ionomer is a variation of conventional glass ionomer, to which methacrylate has been added. It is characterized by lower sensitivity to humidity and better mechanical behavior, thus reducing marginal microleakage and improving its adhesion to dentin. In addition, it has a much-improved resistance to dissolution compared to previous cements $(7,20)$.

The findings of previous studies $(12-14,17,18)$ suggest that, depending on the nature and type of cement, the results are similar concerning the property of sealing crowns at the marginal level. The standardization of the 
test specimens is an essential factor to ensure the correct interpretation of the data; other factors such as the degree of angulation, storage conditions, type of tooth, application of thermocycling techniques could also influence the results, considering the inherent limitations of in vitro studies to reproduce the conditions of the oral environment. It is necessary to consider future studies that can include and control as many of these variables as possible (21).

Some of the limitations of the present study were the accessibility of only one type of microscope for microleakage analysis; more sophisticated techniques such as confocal microscopy may be recommended for linear measurements using photosensitive pigmenting agents. In addition, the use of artificial aging methods for microleakage measurement could generate more accurate values by allowing a closer approximation to oral conditions $(21,22)$.

\section{Conclusions}

In conclusion, in this research, and under the methodology employed, it was observed that there are no statistically significant differences in marginal microleakage in metal copings cemented with zinc phosphate, glass ionomer, and resin-modified ionomer cements.

\section{References}

1. Carey C, Din ND, Lamb J, Wright H, Robb ND, Abuzar M. Survival of single-unit porcelain-fused-to-metal (PFM) and metal crowns placed by students at an Australian university dental clinic over a five-year period. Dent J (Basel). 2021;9:60.

2. Overmeer J, Narby B, Hjalmarsson L, Arnrup K, Eliasson A. A retrospective multicenter study compared metal-ceramic and single composite crowns performed in general public dentistry: 5-year results. Acta Biomater Odontol Scand. 2016;2:43-48.

3. Behr M, Zeman F, Baitinger T, Galler J, Koller M, Handel G, Rosentritt M. The clinical performance of porcelain-fused-to-metal precious alloy single crowns: chipping, recurrent caries, periodontitis, and loss of retention. Int J Prosthodont. 2014;27:153-60.

4. Pjetursson BE, Valente NA, Strasding M, Zwahlen M, Liu S, Sailer I. A systematic review of the survival and complication rates of zirconia-ceramic and metal-ceramic single crowns. Clin Oral Implants Res. 2018:29:199-214.

5. Wassmann T, Schubert A, Malinski F, Rosentritt M, Krohn S, Techmer K, Bürgers R. The antimicrobial and cytotoxic effects of a copper-loaded zinc oxide phosphate cement. Clin Oral Investig. 2020;24:3899-3909.

6. Melo Freire CA, Borges GA, Caldas D, Santos RS, Ignácio SA, Mazur RF. Marginal adaptation and quality of interfaces in lithium disilicate crowns influence manufacturing and cementation techniques. Oper Dent. 2017;42:185-195.

7. Vohra F, Altwaim M, Alshuwaier AS, Deeb MA, Alfawaz Y, Alrabiah M, Abduljabbar T. Influence of bioactive, resin and glass ionomer luting cements on the fracture loads of dentin bonded ceramic crowns. Pak J Med Sci. 2020;36:416-421.

8. Flanagan D. Zinc phosphate as a definitive cement for implant-supported crowns and fixed dentures. Clin Cosmet Investig Dent. 2017;9:93-97.

9. Masaka N, Yoneda S, Masaka K. An up to 43-year longitudinal study of fixed prosthetic restorations retained with 4-META/MMA-TBB resin cement or zinc phosphate cement. J Prosthet Dent. 2021;23:S00223913(21)00212-2.

10. Viani A, Sotiriadis K, Kumpová I, Mancini L, Appavou MS. Mi- crostructural characterization of dental zinc phosphate cements using combined small-angle neutron scattering and microfocus X-ray computed tomography. Dent Mater. 2017;33:402-417.

11. Sidhu SK, Nicholson JW. A Review of glass-ionomer cements for clinical dentistry. J Funct Biomater. 2016;7:16.

12. Ebadian B, Fathi A, Savoj M. In Vitro evaluation of the effect of different luting cements and tooth preparation angle on the microleakage of zirconia crowns. Int J Dent. 2021;2021:8461579.

13. Al-Haj Ali SN, Farah RI. In vitro comparison of microleakage between preformed metal crowns and aesthetic crowns of primary molars using different adhesive luting cements. Eur Arch Paediatr Dent. 2018;19:387-392.

14. Satyendra T, Hima R, Ravi Y, Srinivas K, Krishna H, Kumar S. Evaluation of marginal adaptation and microleakage of all ceramic Crown systems using two commercially available luting agents in vitro study. International Journal of Current Research. 2018;10:7276072765 .

15. Arora SJ, Arora A, Upadhyaya V, Jain S. Comparative evaluation of marginal leakage of provisional crowns cemented with different temporary luting cements: In vitro study. J Indian Prosthodont Soc. 2016;16:42-8.

16. Abad C, Li J, Martinez F, Pradíes G. Correlation between microleakage and absolute marginal discrepancy in zirconia crowns cemented with four resin luting cements: An in vitro study. Int J Dent. 2016;2016:8084505

17. Parameswari BD, Rajakumar M, Lambodaran G, Sundar S. Comparative study on the tensile bond strength and marginal fit of complete veneer cast metal crowns using various luting agents: An in vitro study. J Pharm Bioallied Sci. 2016;8:S138-S143.

18. Eftekhar Ashtiani R, Farzaneh B, Azarsina M, Aghdashi F, Dehghani N, Afshari A, Mahshid M. Microleakage of Four Dental Cements in Metal Ceramic Restorations With Open Margins. Iran Red Crescent Med J. 2015;17:e19611.

19. Rahiotis C, Schricker S. Bonding with glass ionomer cements and resin-modified glass ionomer cements. Orthodontic Applications of Biomaterials. Braz Dent J. 2017;29:253-265.

20. Dermata A, Papageorgiou SN, Fragkou S, Kotsanos N. Comparison of resin-modified glass ionomer cement and composite resin in Class II primary molar restorations: a 2-year parallel randomized clinical trial. Eur Arch Paediatr Dent. 2018;19:393-401.

21. Hepdeniz OK, Ermis RB. Comparative evaluation of marginal adaptation and microleakage of low-shrinking composites after thermocycling and mechanical loading. Niger J Clin Pract. 2019;22:633641.

22. Swapna MU, Koshy S, Kumar A, Nanjappa N, Benjamin S, Nainan MT. Comparing marginal microleakage of three Bulk Fill composites in Class II cavities using a confocal microscope: An in vitro study. J Conserv Dent. 2015;18:409-13.

\section{Ethics}

This study was approved by the Ethics Committee of the Faculty of Health Sciences of the Universidad Privada de Tacna under registry no. 014-2020-FACSA/UPT.

\section{Source of funding}

The authors received no specific funding for this work

\section{Authors' contributions}

Keyla Vargas-Belón: Conception and design of the study, literature review, analysis and interpretation.

Katya Chambilla-Torres: Literature review, writing of the manuscript, final approval of the manuscript.

Marco Sánchez-Tito: Conception and design of the study, analysis and interpretation, writing of the manuscript, final approval of the manuscript.

\section{Conflicts of interest}

All authors declare that they have no conflict of interest to disclose. 